\section{TWO CASES OF GONORRHEAL ARTHRITIS.}

\section{WILLIAM MUDIE, M.D.}

PITTSBURG, PA.

Two eases of septic arthritis, gonorrheal in origin in which both patients were operated on; one terminating fatally, the other in complete recovery, may serve as an illustration of the advantage of prompt surgical interference in this complication of gonorrhea, when contrasted with the so-called expectant plan of treatment. In the case of the patient who died, there was a delay of twelve days from the onset of the septic temperature until the knee joint was opened. In the other case, two days after the septic temperature appeared, both knee joints were opened. In one patient it was an initial attack; in the other, the man had probably lost count of the number of attacks.

CASE 1.-Patient, aged 36, unmarried, a structural ironworker by trade, weight 220 pounds, robust, and the picture of health; had used alcohol to excess on occasions, but could not be called an habitual drinker.

History.-Previous venereal history was negative. The initial symptoms appeared Nov. 15, 1907, within four days after suspicious exposure. He was treated in Chicago and the dis. charge stopped in two weeks. For one week symptoms were absent.

December 8: He came to me with a renewal of the discharge and some preputial edema; he denied venery since first symptoms. Under treatment by urethra irrigations and urinary antisepties the discharge again cleared up in four days. Two dars after he first applied for treatment he reported with a slight pain in the calves of his legs and in one or two metacarpophalangeal joints. The next day the pain in his calves had increased so as to interfere with walking, and additional joints on his hands were involved, but he ascribed his symptoms to the grip, then present in his boarding house. Temperature was 101.

December 12: He was unable to report. His right knee was swollen, hot and painful, with extension of inflammation to the periarticular structures; it was extremely tender on pressure. Pain and swelling in the metacarpophalangeal joints were subsiding; urethral discharge had stopped. Temperature was 102. He was removed to the hospital that night.

Hospital History.-During the first week's stay in the hospital there was a. decided amelioration of all symptoms, under symptomatic treatment with icebags and fixation of the infected knee. The urinalysis showed: Acid reaction, reddish amber color; heavy sediment of urates, specific gravity 1.030; albumin and sugar negative microscopic examination, excess amorphous urates and some uric acid. With the clearing up of the genitourinary symptoms all the infection had apparently centered in the right knee joint, and there seemed to be some grounds for doubt as to whether the arthritis was gonorrheal or ordinary rheumatism.

December 19: The man began to run a septic temperature; at the end of two weeks this changed to a pyemic temperature, with remarkably large daily fluctuations, and continued so, although he was under active stimulation until his death.

Treatment.-At the beginning of his septic state three dry cups were used on the knee joint and a posterior splint was applied. Fluctuation persisted, although the pain had subsided and tenderness was elicited only on rather strong pressure at the head of the tibia.

operation.-December 31, I opened the joint under cocain anesthesia and evacuated about two ounces of seropurulent fluid; double drainage was inserted and the joint cavity flushed with a 1 to 6,000 solution of bichlorid of mercury, followed by a saline solution. Further than a slight drop in temperature this procedure was without effect on the man's general condition. Two days later he had daily, sometimes bidaily chills, followed by drenching sweats, a condition that was typically pyemic, and it daily became more apparent that he was losing ground. Drainage from the joint was insignifi. cant. A long and eareful search of a smear of the pus from the joint failed to reveal bacteria of any kind.

Subsequent Treatment.-Four days before his death, Jan. 14, 1908, I injected under the right breast one cubic centimeter of gonococcic vaccine, containing $50,000,000$ dead bacteria, more in the hope than in the belief that it would do good, but feeling reasonably sure, that, at least in the desperate condition in which the patient then was, it could do no harm. Apparently it had no influence whatsoever. The use of the vaccine is only mentioned incidentally for, as a test for this treatment, it could not be considered fair.

CASE 2.-Patient, aged 34, acknowledged gonorrhea four years ago, with a fairly constant discharge since.

History.-He had a prostatic abscess, with symptoms of stricture; abscess burst in perineum Jan. 13, 1908; this was opened freely, together with a scrotal abscess, at the Mahoning Valley Hospital on the next day. Recovery was uneventful.

February 8: I found him with a double orchitis. He was removed to the hospital. Three days later he complained of pain and tenderness in both knees, in his insteps, over one internal malleolus and particularly in the soles of his feet. On February 15 there was effusion in both knees with a slight rise in temperature; the next day he complained of his left elbow. The only distinctive feature of a urinalysis was the great number of pus cells and bacteria present. The orchitis had subsided.

Operation.-February 17, under general anesthesia both knee joints were opened and drained. Fluid was seropurulent, about an ounce in each joint. Microscopic examination showed the pus cells but no bacteria. All his symptoms immediately began to clear up and in one month be left the hospital with a good pair of knees.

\section{PRIMARY TYPHOID CHOLECYSTITIS AND CHOLANGITIS.}

OSCAR H. WIISON. M.D.

Assistant Demonstrator of Clinical Medicine, Jefferson Medical College; Assistant Registrar Philadelphia General Hospital. PHILADELPHia.

Comparatively few cases of this rather anomalous condition appear in literature. In view of this fact the following case seemed worthy of reporting. It occurred in the service of Dr. S. Solis Cohen at the Philadelphia General Hospital. I feel greatly indebted to Dr. Cohen for the privilege of reporting the same.

Patient.-J. R., aged 52 years, male, white, laborer, was admitted to the Philadelphia General Hospital Lee. 23, 1907. Itis chief complaint, on admission, was intense itching of the skin.

Family History--Parents both deceased; causes of death unknown. No brothers or sisters. No history of tuberculosis, cardiac, renal or malignant disease was obtainable.

Past Medical History.-He had morbilli, pertussis and varicella in childhood. Since that time he has never been confined to bed by illness. When 20 years of age, he had a chancre and specific urethritis. Duration of treatment is unknown. He used tea, coffee, alcohol and tobacco to excess.

Present Illness.-Five weeks previous to admission he fractured several ribs on the left side. Since that time he had suffered with gastric disorders. Vomiting attacks occurred every day; they were unaccompanied by pain, and seemed to bear no distinct relationship to the taking of food. These symptoms he attributed to the fractured ribs. The bowels were obstinately constipated. On the day of admission he suffered with headache, drowsiness and chilly sensations. At this time he first noticed the yellowish discoloration of the skin, which was attended with intense itching.

Examination.-Patient was a well-nourished middle-aged male. His physiognomy was not expressive of any severe pain or discomfort. The skin of his entire body was of a deep golden yellow color. The pupils were equal and reacted to light and 